\title{
Payment Where Payment is Due: Canada's Federal Transfer System and a Needs-Based Solution to Health Transfer Spending
}

MEGAN AIKEN, University of New Brunswick

\begin{abstract}
Since the 1950s, federal transfers have been moulded and remoulded under practically every Prime Minister. The current iteration of transfers, specifically the 2014 implementation of equalper-capita funding through the Canada Health Transfer, poses major problems to regional disparities, and arguably favours provinces that have high growth; this leaves poorer provinces, like the Maritimes, to make major cuts to provincial budgets in order to maintain the standards set out in the Canada Health Act. This paper explores the history of transfers, why transfers are necessary for Canadians, as well as the criticisms of the current system. Following this, it is recommended that a needs-based model for determining health transfers be adopted; specifically, the model developed by Marchildon and Mou that accounts for an aging population as well as one that is geographically dispersed. This paper provides a more contemporary analysis on federal transfers as they relate to the health care system. Additionally, it focuses somewhat on the issues New Brunswick is facing currently as, among other things, a result of inadequate funding from the federal government.
\end{abstract}

Keywords: health policy, public policy, federal transfers, Canada Health Transfer, provincial politics, Canadian politics 


\section{Introduction}

In the world's second largest country in terms of total area, divided into ten provinces and three territories, how is it possible to maintain a sense of unity or cohesion in Canada from coast to coast? This is where the foundation of federalism lies: provinces are under the umbrella of the federal government, where social and fiscal policies are put in place to ensure equal status and opportunity for citizens while still allowing for provincial governments to decide on the specifics of fiscal and social programs. The relationship between the federal and provincial/territorial levels, and to a certain extent the provincial and municipal levels, has been debated and undergone changes since confederation. Stemming from federal-provincial relations is the existence of federal transfers, where the province receives payment from the federal government in order to equalize provincial revenues, or, now, to aid in public service delivery such as healthcare or post-secondary education. There are two types of transfers that can be discussed: equalization as a "horizontal fiscal redistribution" program (Lecours 569), or transfer programs given to all provinces for the purpose of aiding in public service delivery. This paper is more heavily focused on the latter: transfer programs given to provinces for the purpose of public service delivery, specifically health care spending, the Canada Health Act (CHA) and the Canada Health Transfer (CHT).

Over the past fifty years the nature of federal transfers has undergone numerous changes, with the most recent changes having potentially damaging effects on some provincial budgets. It is important to examine the history of federal transfers since the 1950 s and understand where problems have, arguably, always existed in the system. This paper argues in favour of a needsbased solution to federal health transfer spending. In the 2014-2015 fiscal year, alone, \$32.1 billion was spent through the CHT, compared to $\$ 12.6$ billion for the Canada Social Transfer 
(CST) (Gauthier, 2012). This number has been steadily rising for the past ten years, and is expected to rise further due to the aging population along with more demands on the healthcare budget of provinces. Furthermore, relatively new changes to the CHT effectively disenfranchise provinces that do not have sufficient population growth; the federal government, for the past decade, has been accused of deliberately perpetuating inequalities between provinces.

\section{Constitutional Obligations for Equalization}

Maintaining effective federal transfers is crucial to ensuring Canada adheres to its Charter obligations on equalization. The foundation for equalization in Canada is outlined in s. 36 of the Canadian Charter of Rights and Freedoms, which states that

36. (1) Without altering the legislative authority of Parliament or of the provincial legislatures, or the rights of any of them with respect to the exercise of their legislative authority, Parliament and the legislatures, together with the government of Canada and the provincial governments, are committed to

(a) promoting equal opportunities for the well-being of Canadians;

(b) furthering economic development to reduce disparity in opportunities; and

(c) providing essential public services of reasonable quality to all Canadians.

(2) Parliament and the government of Canada are committed to the principle of making equalization payments to ensure that provincial governments have sufficient revenues to provide reasonably comparable levels of public services at reasonably comparable levels of taxation (CA1982).

The federal government, according to the Charter, is obligated to ensure that reasonably comparable public services are available in all provinces and this obligation is carried out 
through equalization as well as, now, with health and social transfers. As is the issue with the Charter and similar legislation, words such as comparably and reasonable are vague enough for the interpretation of section 36 to change, according to the political will and government of the day. Senator Noel Kinsella once called for Canada to create a charter of social and economic rights; in most respects, this charter would build on section 36 of the Charter and give it some "teeth" (Kinsella, 2007). In an era where the federal government is slowly putting more responsibility on the provinces to cover the spending for social programs, it seems unlikely that a charter of social and economic rights is in the near future.

In his essay that compares and contrasts equalization in principle and practice, Douglas H. Clark states that the principles for equalization consist of "clear purpose, effectiveness, equity, efficiency, nation building, accountability, visibility and transparency, sustainability and stability," (Clark, 1969). While the purpose of equalization, a tax revenue redistribution program, is to level the playing field of provincial revenues, the concept has been under scrutiny by political scientists and economists largely from provinces that do not receive equalization payments such as Alberta, British Columbia, and, until recently (2009), Ontario. Furthermore, it has been accused of creating dependency and stagnating provincial economic growth in 'havenot' provinces (Dickson, 1989; McMillan, 2012). Richard Starr argues that, fundamentally, the debate over federal transfers is an ideological issue stemming from a Fraser Institute 1978 collection of essays which has since gained traction (Starr, 2014). Whether the debate has been fuelled by ideology or not, Canada's federal transfer programs have been moulded and remoulded for the past half-century into current programs that are unsustainable, arguably do not fulfill the federal government's constitutional obligations, and force historically 'have-not' 
provinces into inescapable levels of debt while also forcing historically wealthy provinces into being labelled 'have-not'.

\section{Background: Fifty Years of Transfers}

Before thoroughly examining the current situation in fiscal federalism as well as potential solutions, it is important to overview the history of transfer payments and how the relationship between the federal and provincial government has changed dramatically since the 1950s. This will give the needed context to best understand the current situation, where transfer payments other than equalization are largely based on demographics and population growth, and thus put more responsibilities on provinces that struggle with population growth. As one can guess, much of the discourse surrounding equalization and transfer payments has to do with the impact on Atlantic Canada; historically, Nova Scotia, New Brunswick, Prince Edward Island and, to a lesser extent, Newfoundland and Labrador, have the reputation for being relatively poor provinces. More recently, much of the discussion has surrounded Ontario; first with the controversial Mowat Center reports on equalization and then Ontario Premier Wynne's "Fairness for Ontarians" slogan to raise awareness that the province was being short-changed by the federal government (Starr, 2014).

\section{Equalization}

Canada's first iteration of federal transfers began in 1957 with equalization payments by the St-Laurent government. Equalization was, and still is, based on a formula to determine which provinces are in need of assistance in order to bring them up to a benchmark. Originally, this formula was based on determining the per capita tax yield of all provinces - the highest two in 
1957 being Ontario and British Columbia, averaging them, then aiming to bring all other provinces up to that average through redistributing the taxed revenues collected by the federal government (Starr, 2014). When this program originally began, the taxes used to determine a province's yield were personal income tax, corporate income tax, and inheritance tax; since then, taxes such as natural resource tax are also considered (Starr, 2014). The government might collect a little more in order to distribute wealth more equally throughout the country, but for the most part the redistribution has been from already taxed revenues from the provinces.

\section{Cost-Sharing Arrangements}

Later in the 1960s, cost-sharing arrangements were put in place, such as Medicare (1966), Hospital Insurance, the Federal-Provincial Fiscal Arrangements Act 1967 for post-secondary education, and the Canada Assistance Plan (CAP), which was a "50/50 cost-sharing program covering eligible expenditures that provincial, territorial and municipal governments incurred in providing social assistance and welfare services," (Gauthier, 2012). The term cost-sharing is associated with this period in federalism because the costs for these programs were shared by the provincial and federal governments; in exchange for funding, there would generally be guidelines for provinces to follow if they were to receive the full funding available to them. While the healthcare sector and other social services are primarily under jurisdiction of the provinces, and have been since confederation through the Constitution of 1867, the federal government helps fund many of these programs to ensure all Canadians have access to them. What should be noted is that these cost-sharing programs are not based on an equal-per-capita basis, meaning "the level of federal support reflected both provincial and territorial spending decisions and the specific labour market circumstances of each province and territory," (Gauthier, 2012). 


\section{Established Programs Financing and an end to Cost-Sharing}

During the Pierre Trudeau era, in 1977, the Established Programs Financing (EPF) was created and combined all federal transfers other than equalization and CAP (Dept. Finance, 2014). Rather than being a cost-sharing program, the EPF was made up of two sources of funding: tax transfer and cash transfer. "The value of the tax points grew in line with the economy. The growth rate of the cash transfer was modified several times as the program underwent changes throughout the years," (Dept. Finance, 2014). When the CHA was created under Trudeau's second run as Prime Minister in 1984, the EPF was used as a bargaining tool for provinces to follow the guidelines set out in the CHA: "EPF funding was made conditional on respect for the five criteria of the Canada Health Act (universality, accessibility, portability, comprehensiveness, and public administration) and provisions for withholding funding were introduced," (Dept. Finance, 2014). While guidelines are necessary for funding, the government ran into issues with penalties for failure to comply with the CHA, especially considering a number of growth limitations placed on EPF funding. In a review of the Canada Health and Social Transfer for the federal government, Odette Madore writes that:

Until 1991-1992, penalties for failure to comply with the CHA were applied only against cash transfer for EPF-Health; however, they were later also applied against other provincial entitlements. This extension of financial penalties to cash transfers under other federal programs was made necessary by the continual limitations placed on the growth rate of EPF transfers [by the federal government] and the particular effects of such restrictions on the cash transfers; it was estimated that EPF-Health cash transfers to some provinces would have reached zero by the end of the century. Without the cash transfer, 
the federal government would no longer have had the power to enforce the CHA's requirements. (Madore, 2003).

Funding could also be withheld if provinces did not adhere to certain standards for other programs. One example concerning the CAP occurred in 1995, when the Government of British Columbia "decided to impose, starting on 1 December 1995, a three month residency requirement before individuals could receive social assistance. That same month, the Honourable Lloyd Axworthy, then federal Minister then responsible for CAP, announced that CAP transfer payments to British Columbia would be reduced by $\$ 47.1$ million," (Madore, 2003). In some regards, while potentially restrictive, this incentivized the provinces to maintain certain standards for accessing public services.

\section{Creating one Fund for Transfers: the CHST, and "Equal per Capita"}

The 1995-1996 federal budget completely changed the landscape of Canada's federal transfer system. Where there had previously been some form of conditional granting, or costsharing arrangement, the Chretien government combined the CAP and EPF into one fund, the Canada Health and Social Transfer (CHST) (Dept. Finance, 2014). This essentially combined funding for health care, post-secondary education, social assistance, and social services into one giant block fund. Its funding model took after the original 1977 EPF formula, which included tax transfer and cash transfer portions; however, the total amount of funding to a province was allocated on an "equal per capita basis" (Dept. Finance, 2014). Madore writes that "it was felt that the CHST would give the provinces more discretion over how funds were to be divided among health care and other social programs. More provincial flexibility, however... led to reduced federal visibility and transparency in these fields and diminished provincial accountability for how federal transfers are spent," (Madore, 2003). 
During the 1990's spending cuts were occurring throughout the country:

- Frank McKenna, premier of New Brunswick, made cuts to public services like school boards, hospital boards, public sector wages and jobs;

- PEI's Catherine Callbeck also cut civil service jobs and wages;

- John Savage of Nova Scotia followed New Brunswick and PEI, but also raised taxes;

- Saskatchewan's Roy Romanow implemented program cuts and tax increases;

- Ralph Klein, Alberta's Premier at the time, "eliminated [Alberta's] deficit entirely through spending cuts totalling 20 per cent between 1993 and 1996;"

- Ontario's Premier Mike Harris looked to the US for more economic growth through trade as well as cutting spending and raising taxes (Starr, 2014).

The whole country was truly in economic turmoil; the federal government, too, ended up cutting program spending mostly in the form of cutting federal transfers to the provinces. Whereas Mulroney had already "reduced federal spending from 20 to 17 per cent GDP," Richard Starr accused the Chretien government of destroying Canada's welfare state; he wrote that "the already tattered welfare state was ripped pretty much to shreds," (Starr, 2014). These spending cuts really surfaced in the newly formed CHST in 1996. In 1995 combined EPF and CAP spending was $\$ 16.25$ billion for the provinces; this number dropped to $\$ 12.45$ billion with the singular CHST in 1996, then again down to just \$9.85 billion in 1997 (Starr, 2014). While the government of the day claimed that spending was being cut proportionally across the board, this was simply not the case. In 1996 CHST spending was cut by $18.9 \%$, whereas all other federal program spending was only cut $1.4 \%$; in 1997 CHST spending was cut another $16.7 \%$ whereas all other program spending was only cut by $0.5 \%$ (1995 Federal Budget).

\section{A Change in how Funds are Transferred}

Aside from spending cuts, the move from EPF/CAP to CHST is also important due to the new way the funds are transferred. Before, there were cost-sharing arrangements to ensure that provinces were maintaining some level of comparable public services; as explained earlier, if 
provinces did not uphold these obligations, their funding was on the line. In general, the cost of programs was shared equally by the federal government and provinces. However, the CHST was created as a block transfer. With one fund being given in one block, the federal government had no way to determine what was being spent on health or what was being spent on post-secondary education or welfare/social programs. While provinces were still on the hook for adhering to the CHA due to its implementation, block funding made it so that the federal government had no clear way of knowing how much of the funding was going to healthcare and how much was going to other areas like post-secondary education or social programs. Noticing this emerging issue, the federal government separated the CHST in 2003 into two funds: the Canada Health Transfer (CHT) and the Canada Social Transfer (CST). Rather than cost-sharing arrangements where the federal government covered a certain percentage of the costs associated with programs covered under the fund, the CHT and CST were still block funds. Roughly " $62 \%$ of the [previous] CHST tax transfer [was] allocated to the CHT, while the remaining 38\% [was] devoted to the CST... the total entitlement of the two transfers [were projected to] grow in line with the [previous] cash and tax transfers. Total entitlements [were then to be] allocated among the provinces on an equal per capita basis" (Madore, 2003).

\section{The Current Situation: 2014-2015 Changes to Transfers}

Equal per capita transfers are not a new concept; certain portions of transfers had been equal per capita based since the EPF, however, the issue that has surfaced most recently was the Harper government's decision to remove the "equalizing component of the CHT by legislative that the cash transfer move to an equal-per-capita allocation in 2014-2015," (Deraspe, 2011). One issue arising can be seen in New Brunswick. The province has a rapidly aging population and sees two of every five publicly spent dollars going to health care (Saillant, 2014). For New 
Brunswick, the total costs needed to cover health care adequately for every citizen cannot be accounted for by a per capita calculation (Saillant, 2014). While a per capita calculation sees just a population, the real picture is that there are varying levels of needs within that population. This is true for all provinces. The issue that New Brunswick is facing, with other provinces following suit, is its rapidly aging population. In 2015 , for the first time, the province recorded more deaths than births. To give an idea of the impact on an economy that a disproportionately high elderly population can have on an economy, consider the research conducted by the Canada Institute for Health Information; a 2011 report showed that, "although [the elderly] make up only 14\% of the population [of Canada], in 2009-2010, 40\% of acute hospital stays were for patients 64 and older" (CIHI 2011).

The equalizing portion of the CHT was removed beginning in 2014-2015 because the federal government believed that "interprovincial equity [was] more appropriately addressed through the Equalization program," (Deraspe, 2011). What this new formula fails to recognize is that "there is a difference between equity and equality and treating everyone exactly the same may not always be fair" (Di Matteo, n.d.). Equality connotes that everyone taking from the pot receives the same amount, regardless; they are receiving equal treatment. Equity, on the other hand, implies that, of those taking from the pot, the amount they are taking will bring everyone up to an equal benchmark in order to make up for advantages and disadvantages. In Canada, "the provinces are not equal in their rates of population growth, the rates at which their population is aging, the proportion of aboriginal or immigrant population, or the incidence of various diseases. As a result, their differences can and, many would argue should, be a factor in provincial variations in per capita health spending" (Di Matteo, n.d.). By relying solely on the Equalization program to account for interprovincial equity, the federal government overlooks the 
disadvantages that some provinces face. An effective health care funding model would ensure that all Canadians had the appropriate means and tools needed to maintain good health.

Table 1

\begin{tabular}{|l|r|r|r|}
\hline \multicolumn{5}{|c|}{ PROVINCIAL CHT CASH ENTITLEMENTS (\$M) } \\
\hline & $2013-2014$ & $2014-2015$ & \multicolumn{1}{c|}{$\%$ Change } \\
\cline { 2 - 4 } NL & 489.7 & 489.7 & $0.00 \%$ \\
PEI & 128 & 131.2 & $2.50 \%$ \\
NS & 829.9 & 846.8 & $2.00 \%$ \\
NB & 666.6 & 682.4 & $2.40 \%$ \\
QC & 7183.8 & 7426.7 & $3.40 \%$ \\
ON & 11925.1 & 12334.9 & $3.40 \%$ \\
MB & 1114.4 & 1156.3 & $3.80 \%$ \\
SK & 976.6 & 1019.3 & $4.40 \%$ \\
AL & 2722.9 & 3750.9 & $37.80 \%$ \\
BC & 4154.4 & 4169.5 & $0.40 \%$ \\
YT & 31 & 33.4 & $7.70 \%$ \\
NT & 27 & 39.2 & $45.20 \%$ \\
NU & 33.7 & 33.7 & $0.00 \%$ \\
\hline
\end{tabular}

\section{Amount of Funding Provinces Receive}

The striking advantages and disadvantages inherent in this funding strategy become apparent in Table 1 (next page). This shows the percent change in CHT entitlements before and after the equal per capita changes occurred for 2014-2015. For the years just before these changes were implemented, CHT total entitlements had been growing at 6 percent annually. While this shows escalating growth, when a breakdown of entitlements for each province is displayed one can see that the total entitlements do not paint a complete picture of distribution between the provinces. Notwithstanding the territories, Alberta now receives the most funding through CHT with a $37.8 \%$ increase for the first year under the new funding model. 
Newfoundland did not change and British Columbia only increased by .4\% (Nadeau, 2014). The Maritimes all received between 2.0\% and 2.5\% increase, and all other provinces saw increases between $3.4 \%$ and $4.4 \%$ (Nadeau, 2014). While equal per capita health care funding may, in theory, aid provinces that have the largest populations and require massive health care spending, this model does not accurately represent all the other factors that play into how much spending is needed for provincial health care, regardless of upholding a reasonably comparable level of it to other provinces.

\section{Is Equal-per-Capita Right for Canada?}

Reaction to the move toward equal-per-capita funding for the CHT was, for the most part, swift and merciless. Michael McBane of The Hill Times argued that the government was going to make it "next to impossible for provinces to provide health care services on equal terms and conditions" (McBane, 2014). Shortly after the change was announced, Josh Wingrove for The Globe and Mail argued that the per-capita health transfer was a "windfall [for Alberta] that comes at the expense of every other province" (Wingrove, 2012). In 2015, the Canadian Federation of Nurses Unions released a report criticizing the changes and cuts to transfer spending. In their critique, they argued that there is the "lack of a relationship between funding and the costs of delivering health care" (Mackenzie 25, 2015). This is because the move toward equal-per-capita was announced without provincial consultation and without consideration for, specifically, the cost of an aging population. This report also speaks to the disconnect between the CHT and the equalization provisions in the constitution by noting that while "the Act would appear to require that equalization programs make some attempt to measure and assess levels of service, in practice what has been equalized is not service but revenue" Mackenzie 25, 2015).

One of the reasons for switching to equal-per-capita for the CHT was that the government argued equalization should not occur in health transfers; that health transfers should solely be about supplementing the provinces in funding the provision of health care. What this severely neglects is that the provision of health care is, increasingly, the most expensive public service available to Canadians. If equalization is needed anywhere, it would be within the healthcare sector. Furthermore, to argue that equalization should only be accounted for by the Equalization 
program also neglects the fact that the level of funding available through Equalization and the CHT are not even comparable. Even after cuts to the total amount of funding available, the CHT and CST combined represent almost $\$ 50$ billion of transfer funds for all provinces in 2015-2016 (Mowat Centre, 2014). Comparatively, for the same year the Equalization program totals $\$ 17.3$ billion (Mowat Centre, 2014). If the sole purpose of the Equalization program is to fulfill those constitutional obligations while receiving less than required health transfers, then provinces would be hard pressed to cover just the health care sector without receiving adequate assistance in another form.

\section{Solutions to the Problem: More Reliable Research Required}

When discussing the next steps in how to address the issue of health care funding to provinces, it is absolutely paramount that a pan-Canadian study be conducted to better understand how the provinces use the resources they have and are given; any research must include qualitative data in order to demonstrate where shortfalls may lie within each province - something that statistics may not be able to accurately describe. While it could be argued that this has been done, specifically in 2013 with the Fraser Institute's Provincial Health Care Index, the Institute's conclusions and cost-value based analysis appear rather dubious in an effort to criticize the overall universal healthcare system. Furthermore, the Institute's cost-value approach does not fully address the issue; while New Brunswick might spend the least on healthcare per capita and Alberta might spend the most, factors such as the overall age or well-being of the population, or relatively easy access to physicians is not addressed (Barua, 2013). Furthermore, while Alberta may spend more on healthcare, which is not necessarily bad, provinces are allocated funding specifically for the purposes of health care through the Canada Health Transfer. Therefore, provinces that receive the most will 
clearly spend the most. The main difference between these two provinces, and why the inequality is so apparent even though they may be treated equally, is that growth and population is far from being the only determining factor in how expensive the provision of health care within a province can be. Furthermore, the fiscal capacity of a province must be considered in order to compare accurately.

\section{Research Conducted to Date}

In the past 60 years of equalization and transfer programs, it could be argued that there has likely never been consensus among the provinces that any given model has fully addressed the needs of each province. Practically since confederation, the Maritimes and Quebec, in particular, have been seen as reaping the rewards of the West's hard work. Since the CHT changes that took effect in 2014 were announced in 2007, lobby and research organizations have come forward with solutions to the issue of growing healthcare costs with ineffective funding from the federal government. Two suggestions have been to implement the following:

- A series of reforms to the Canada Health Act (Clemens, 2012).

- A needs-based or expenditure-based formula that accounts for a province's needs and forecasted expenditures (Marchildon and Mou, 2013; Bird and Vaillancourt, 2007).

\section{Reforming the Canada Health Act}

In 2012, Jason Clemens and Nadeem Esmail of the Macdonald-Laurier Institute published a report on how the $C H A$ obstructs reform and innovation, and constrains provinces with regards to how block funding is used. The $C H A$ is based on five core areas that act as the foundation for Canada's universal healthcare system:

- Public Administration,

- Comprehensiveness,

- Universality, 
- Portability, and

- Accessibility (Madore, 2003).

Section 18 of the $C H A$ states, "in order that a province may qualify for a full cash contribution... for a fiscal year, no payments may be permitted by the province for that fiscal year under the health care insurance plan of the province in respect of insured health services that have been subject to extra-billing by medical practitioners or dentists," (CHA s. 18). Section 19 expands the previous section to include restricting user fees with the exceptions of the accommodation and meal payments of chronic care/long-term residents of hospitals ( $C H A$ s.19). Keeping in mind the importance of the Act, Clemens and Esmail suggest a total of four reforms to the CHA that would give provinces more autonomy in moulding their healthcare systems to best fit each unique situation.

The first reform is to section 8 , regarding public administration. This section "creates the single insurer structure of Medicare, making competition in universal insurance impossible," (Clemens and Esmail, 2012). They argue that provinces should be allowed the freedom "to determine their own health care policies" with regards to insurance plans and how they are operated/regulated (Clemens and Esmail, 2012). The second suggested reform is under section 10, universality; while they believe the foundational point of universality in healthcare should be maintained, they argue for an amendment to this section, which would allow for more open competition and personalization of universal insurance in each province (Clemens and Esmail, 2012). Section 12 ties closely with s. 36 of the Charter, in that it introduced the "undefined concept of reasonable access," (Clemens and Esmail, 2012). It details how healthcare policies are to be structured in such a way that they're relatively parallel province-to-province. The recommended reform for this is to set baseline parallel policies for low-income citizens, but 
allow provinces more interpretational freedom for the middle and high-income earners in each province (Clemens and Esmail, 2012). Finally, they suggest that all sections of the CHA pertaining to extra billing and user charges be repealed entirely; they argue that these sections "[restrict] any sharing of costs between private payers and the public system," (Clemens and Esmail, 2012).

While amending the CHA to allow for more provincial autonomy in healthcare spending seems like a fine solution, there could be unforeseen consequences. One such consequence could be shrugging off s. 36 of the Charter, which talks about reasonably comparable services. In Clemens and Esmail's analysis of the reforms, it seems as though giving the provinces this level of autonomy could easily undermine s. 36 by giving provinces too much freedom in reforming the individual healthcare systems within each province, especially considering the regional disparities and level of low-income earners in some provinces compared to others. Furthermore, reforming the CHA may not address the root of the issue, which is poor policy decisions regarding federal transfers.

\section{Adopting a Needs-Based Funding Model}

In an article on promoting a needs-based funding formula for the CHT as an alternative to the equal per capita method, Marchildon and Mou propose that a more comprehensive funding formula that would reflect Canada's constitution equalization obligations better would be to adopt a needs-based, or expenditure-based, health transfer formula. Specifically, they argue that by accounting for the age of a population, as well as geographical distribution (level of isolated or rural population within a region), a fairer funding model could be implemented. They argue that the original purpose of the CHT was "oriented to the expenditure side: to get provincial governments to provide universal hospital and medical care coverage under a defined set of very 
high-level national standards" (Marchildon and Mou, 2014). This, in the beginning, was significantly different from the Equalization program that supplemented the revenues of provinces with a lower than average revenue-generating capacity. However, they explain that somewhere around the time that the health transfer turned into a block fund in 1977, the lines between these two funding programs became blurred. When the Canadian government did away with the block fund method, the expenditure-based funding formula did not return. The basic principle of needs-based funding is that "the characteristics of a population should drive its relative need for health services" (Marchildon and Mou, 2014). Some provinces such as British Columbia, Alberta, and Saskatchewan, at the provincial level, have "adjusted their per capita allocation based on age, gender, and socio-economic status of the population," from the Ministry of Health to the provinces Regional Health Authorities (Marchildon and Mou, 2014). As such, within Canada there have already been successes in adopting this funding mode.

Age plays an important factor in healthcare spending in two ways: in a 2013 average, Medicare expenditures were highest for infants and those aged 55 and above, exponentially rising for age brackets higher than 55-59 (Marchildon and Mou, 2014). While age plays an important role in determining how expensive a province's total healthcare system is, it is not the only factor. Marchildon and Mou argue that geographical distribution of population should also be considered in a needs-based formula: "more than half of the Canadian population resides in the highly urbanized provinces of Ontario and Quebec, and the 13 provinces and territories have quite different patterns of population dispersion within their boundaries" (Marchildon and Mou, 2014). This can create rural-urban disparities due to poor access to healthcare infrastructure and professionals in more rural areas; this "is a contributing factor to the poorer health status of rural residents compared with their urban peers," (Marchildon and Mou, 2014). Furthermore, a 
chronically underfunded system can trigger compounding needs for healthcare. Without access to infrastructure and healthcare professionals, health issues can compound and result in higher costs if left untreated. Marchildon and Mou focus on these two needs factors because they are arguably completely out of the hands or control of the provinces, and, thus, the provinces should not be held accountable; they argue that having an only equal per capita block fund for CHT creates and exaggerates the already prominent disparities between provinces with older and more geographically dispersed populations.

If the model Marchildon and Mou propose were to be implemented, "Alberta [would have] the most to lose, while [Newfoundland and Labrador] would have the most to gain," (Marchildon and Mou, 2014). A total of eight provinces would gain, under this model, and two provinces would lose as a result of the adjustments.

British Columbia, Saskatchewan, New Brunswick, Nova Scotia, and Newfoundland [would] receive more CHT funds because they have older-than-average age profiles and higher-than-average geographical dispersion. Quebec and Prince Edward Island would receive a larger transfer because their relatively "old" age profiles outweigh the effect of lower-than-average geographical dispersion, while Manitoba would receive more funding because its relatively high geographical dispersion outweighs the effect of its relatively young population. Ontario would lose the most (C $\$ 370$ million) because of its relatively young and highly urbanized population, followed by Alberta, which would lose C $\$ 312$ million, primarily because of its even younger age profile. (Marchildon and Mou, 2014).

In order for a policy such as this to be implemented, it could be argued that a culture shift within Canada would need to take place. Provinces such as British Columbia and Saskatchewan, as 
mentioned earlier, have already adopted similar models at the provincial level; those provinces in particular are known to be relatively progressive and, adopting such a model country-wide would likely require major negotiations between the federal and provincial governments. The first hurdle in adopting a needs-based health transfer model would be for the federal government to obtain the political will for change in this area, and realize that without accounting for a number of indicators, such as age or geography, citizens in one part of the country are absolutely not receiving reasonably comparable health services to other citizens in a more growth-driven area.

\section{International Success with Needs-Based Transfer Formulas}

Internationally, there has been some success with needs-based transfer formulas, at all levels of development. From these examples, best practices can quickly be picked out and it becomes easier to draw connections to how Canada could adopt such a model. Similarly to Canada, Australia collects a large amount of public sector revenues from its sub-national levels in order to redistribute in such a way that, "if each [sub-national government] each made the same effort to raise revenue from its own sources and operated at the same level of efficiency, each would have the capacity to provide services at the same standard," (Bird and Vaillancourt, 2007). Australia's method of determining the needs of a sub-national government have existed since 1933 and are re-evaluated on a five year basis "employing a very comprehensive approach using 18 revenue and 41 expenditure categories," (Bird and Vaillancourt, 2007). Some of these determinants include proportionality of age groups, unemployment rate, and per capita demand for in-patient hospital services.

Germany's constitution is similar to Canada's in one way: it guarantees equal living conditions in all parts of the country. The wording, however, is slightly stronger than Canada's equalization obligation of reasonably comparable public services. Nevertheless, Germany uses 
expenditure/needs-based formula in order to determine funding to the sub-national levels. Germany actually has three equalizing transfer programs; the purpose of two of these is to bring the fiscal-capacity of financially weaker states to a certain benchmark of the national average, around 90\% (Bird and Vaillancourt, 2007). They also note that Germany has the "most equalizing system found in federal countries," though it has received criticism for penalizing wealthier states and "encouraging fiscal irresponsibility" in poorer states - something with which Canada also has experience (Bird and Vaillancourt, 2007).

\section{Conclusion}

This paper has overviewed the history of federal transfers in Canada and how, for the most part, disparities have been manufactured and perpetuated by a flawed system that does not account for the individual needs of each province, specifically with regards to health care spending. Canada does not have one unifying health care system, it has thirteen; the government must recognize this as fact and allow, to a certain extent, provinces more autonomy over how health care is delivered. Furthermore, it is essential that the Government of Canada recognize that there are more determining factors to how expensive a province's health care costs are than the growth of their population. Two major solutions have been put forth on how to deal with health transfers; the first being to reform the Canada Health Act and the second being to adopt a completely different funding model for the CHT. Reforming the Canada Health Act for the reasons discussed is, arguably, not in the best interests of all provinces, specifically because Medicare is one of the cornerstones of the Canadian identity and all citizens should have access to similar services no matter where they choose to reside in the country. The recent move to total equal-per-capita block funding for the CHT is only beneficial to one province (Alberta) and one territory (Northwest Territories); all other provinces lose out in this situation. Unless a needs- 
based model such as the one that Marchildon and Mou developed is implemented, provinces will be plunged further into debt partly due to increasing demands on the health care system, with a government that does not have the political will or capacity to mitigate it. There has been success with such a model, provincially, and internationally where other countries have adopted funding models that are based on expenditures and the needs of a jurisdiction. 


\section{References}

"Federal transfer payments - what you need to know: The Mowat Centre." (2014, December 16).

Bird, R. and F. Vaillancourt. 2007. ' Expenditure-Based Equalisation Transfers.' In Fiscal Equalization: Challenges in the Design of Intergovernmental Transfers, ed. J. MartinezVazquez and B. Searle. New York: Springer

Canada. Office of the Parliamentary Budget Officer. 2014-2015 Federal Transfers to Provinces and Territories. By Jean-Francois Nadeau. Ottawa: Government of Canada, 2014. Print.

Clark, Douglas H. Fiscal Need and Revenue Equalization Grants: By Douglas H. Clark. Toronto: Canadian Tax Foundation, 1969. Print.

Clemens, Jason, and NadeemEsmail. "First, Do No Harm: How the Canada Health Act Obstructs Reform and Innovation." Macdonald-Laurier Institute (2012): 1-42. Web.

Deraspe, Raphaelle, and James Gauthier. "Canada Health Transfer: Equal-Per-Capita Cash by 2014." Library of Parliament.Parliament of Canada, 2011. Web.

Dickson, Vaughan A, and David Murrell. Is Atlantic Canada Becoming More Dependent on Federal Transfers?: A Comment. Fredericton: Dept. of Economics, University of New Brunswick, 1989. Print.

Di Matteo, Livio. "Canada Health Transfer Changes: The Devil Is in the Details." Evidence Network. EvidenceNetwork.ca, n.d. Web.

Gauthier, James. The Canada Social Transfer: Past, Present and Future Considerations. Ottawa: Library of Parliament, 2012. Internet resource.

Health Care in Canada, 2011: A Focus on Seniors and Aging. Publication. Canadian Institute for Heath Information (CIHI), 2011. Web.

Kinsella, Noel A. "Can Canada Afford a Charter of Social and Economic Rights?" Chains \& Links: Human Rights Activism Conference. University of Saskatchewan, Saskatoon, SK. 1 Nov. 2007. Speech.

Mackenzie, Hugh. (2015). The Canada Health Transfer Disconnect: An Aging Population, Rising Health Care Costs and a Shrinking Rederal Role in Funding (p. 45). Ottawa, 
Ontario: The Canadian Federation of Nurses Unions.

Madore, Odette. The Canada Health And Social Transfer: Operation And Possible Repercussions On The Health Care Sector. Ottawa: Government of Canada, 2003. Print.

Marchildon, Gregory, and HaizhenMou. "A Needs-Based Allocation Formula for Canada Health Transfer." Canadian Public Policy (2014): 209-23. Web.

Marchildon, Gregory, and HaizhenMou. "The Funding Formula for Health Care Is Broken. Alberta's Windfall Proves It." The Globe and Mail. N.p., 9 Oct. 2013. Web.

McBane, Michael. (2014, February 17). Budget 2014 triggers Harper's plan to dismantle national health care. The Hill Times.

McMillan, Melville L. "Alberta And 'Equalization': Separating Fact From Fiction Or Sorting Out Some Implications And Options In Canadian Fiscal Federalism." Western Centre for Economic Research Information Bulletin (2012): 85 pag. Web.

Murrell, David. Recent Issues in Equalization Payments As They Pertain to Atlantic Canada. Fredericton: Dept. of Economics, University of New Brunswick, 2002. Print.

Report F: Canada Health and Social Transfer. Rep. Government of Canada, n.d. Web. 1996. Saillant, Richard. Over the Cliff?: Acting Now to Avoid New Brunswick's Bankruptcy. Moncton, NB: Canadian Institute for Research on Public Policy and Public Administration, 2014. Print.

Starr, Richard. Equal As Citizens: The Tumultuous and Troubled History of a Great Canadian Idea. , 2014. Print.

Wingrove, Josh. (2012, January 17). Ottawa's per-capita health transfers a windfall for Alberta. The Globe and Mail. 